\title{
Collaborative Versus Adversarial Stances in Scientific Discourse: Implications for the Role of Systematic Case Studies in the Development of Evidence-Based Practice in Psychotherapy*
}

\author{
DAVID J.A. EDWARDS ${ }^{\mathrm{a}, \mathrm{b}}$
}

\author{
${ }^{a}$ Rhodes University, South Africa \\ ${ }^{\mathrm{b}}$ Correspondence concerning this article should be addressed to David J.A. Edwards, Department of \\ Psychology, \\ Rhodes University, Grahamstown, 6140, South Africa \\ Email: D.Edwards@ru.ac.za \\ *Notes: (1) This is an expanded version of a paper presented at the 37th Annual Conference of the Society for \\ Psychotherapy Research, Edinburgh, Scotland, June 21-24, 2006 on a panel, "A Marriage Made in Heaven: \\ Systematic Case Studies and Psychotherapy Research.” This paper incorporates comments on several \\ contributions, formal and informal, to that conference. (2) Preparation of this paper was supported by grants \\ from the National Research Foundation (South Africa) and Rhodes University's Joint Research Committee.
}

\begin{abstract}
There is still a need for advocacy in the promotion of case study research because there has been insufficient appreciation of its role as a source of evidence relevant to the development and evaluation of practice in psychotherapy. Distorted use of terms like "gold standard," "anecdotal," and "empirical" in the discourse in which research methodology is typically presented has disempowered the practitioner's perspective and discredited the role of case-based knowledge building. The framework of evidence-based practice (EBP) recognizes the complementarity of different research methods and acknowledges the significance of casebased research. To spell out some of these complementary links, a typology of seven research methods - including both experimental group comparison designs and individual case studies is proposed and the contribution of each to the development of EBP is set out. Finally some suggestions are made for strategies to promote the publication of high quality case studies.
\end{abstract}

Key words: evidence-based practice; systematic case studies; scientific discourse; clinical knowledge building; randomized control trials (RCTs)

There is still a need for advocacy in the promotion of case study research because there has been insufficient appreciation of its role as a source of evidence relevant to the development and evaluation of practice in psychotherapy. Miller and Miller (2005, p. 70) observe that there is considerable inconsistency with respect to the role of evidence and proof in science, and it is not uncommon for authors to shift between two different positions. On the one hand, there is an idealized demand for "objective certainty" in the establishment of absolute truths, which means that "only a narrow range of evidence" can be admitted and very little can be said with confidence. On the other hand, there is the reality of everyday practice within which "[s]ubjective opinions and consensus among scientists often supersede the stricture of irrefutibility" and "scientific standards of proof are not uniform and well-defined." 
Collaborative Versus Adversarial Stances in Scientific Discourse:

Implications for the Role of Systematic Case Studies

D.J.A. Edwards

Pragmatic Case Studies in Psychotherapy, http://pcsp.libraries.rutgers.edu

Volume 3, Module 1, Article 2, pp. 6-34, 03-01-07 [copyright by author]

This reflects the fact that the development of scientific knowledge and understanding is not only a rational but also a social process (Kuhn, 1962). The social dimension is framed within an important polarity, two contrasting stances with different priorities and different agendas, which shape attitudes and decision making. There is a collaborative pole, characterized by a degree of mutual trust that colleagues will uphold basic standards of research and be honest and act with integrity as they work together to advance knowledge and map out a new field or extend and refine knowledge in an old one. This can be contrasted with an adversarial pole, characterized by mistrust, a readiness to critically dismiss new findings or discredit new hypotheses and demands for absolute standards of proof. All applications of science must harmonize these two opposing positions. With too much emphasis on the collaborative pole scientists can get caught up in offering as established scientific fact what are merely inadequately founded hypotheses that are later discredited. With too much emphasis on the adversarial pole doubt can be cast on virtually any claim and it is easy to discredit research which provides evidence for a conclusion that does not fit one's misconceptions.

This distinction is not the same as the classical one between the phase of discovery and the phase of verification in science (Giorgi, 1986). No doubt, the open-minded, explorative stance of the collaborative pole is especially suited to the phase of discovery, while the critical stance of the adversarial pole may play a role in the phase of verification in that it may prompt an active search for alternative explanations and ways of rigorously testing hypotheses.

However, what characterizes the distinction between the collaborative and adversarial poles is the degree of personal investment that individual scientists have in particular theories or ideological positions. Such investment compromises the neutrality which is required for balanced scientific endeavor. Those who personally identify with particular positions are vulnerable to feelings of loss or failure if cherished theories are challenged or disconfirmed (Mitroff, 1974), and may protect themselves by rigid thinking and hostility towards those who hold positions that challenge them. Psychotherapy research is a domain where this is particularly prominent. There is ongoing conflict between the discourses of different schools of psychotherapy. Dattilio and Norcross (2006) comment on the surprising degree of resistance in some quarters to integration of concepts and practices that evolved within different schools:

Aspects of ego identification and a territorial imperative are hypothesized to be at the core of some resistance. If the human instinct of territoriality is indeed one cause, such resistance may be difficult to change and may forever limit the potential and acceptance of psychotherapy integration, or even the appreciation for what other modalities have to offer. (2006, p. 5)

An overemphasis on the adversarial pole has also contributed to the gulf between researcher and practitioner, about which commentators have expressed concern for a quarter of a century (Lampropoulos, Goldfried, Castonguay, Lambert, Stiles, and Nestoros, 2002; Mahrer, 1988; Polkinghorne, 1986; Safran, Greenberg and Rice, 1988; Strupp, 1981). Many researchers have seen themselves as engaged in a process of knowledge building that is superior to that which occupies most practitioners in the field. Goldfried observes that some university-based "scientists" distance themselves from the front-line of clinical practice and 
Collaborative Versus Adversarial Stances in Scientific Discourse:

Implications for the Role of Systematic Case Studies

D.J.A. Edwards

Pragmatic Case Studies in Psychotherapy, http://pcsp.libraries.rutgers.edu

Volume 3, Module 1, Article 2, pp. 6-34, 03-01-07 [copyright by author]

even openly express contempt for practitioners and their approach to knowledge development (Lampropoulos et al, 2002). Practitioners, in turn, have tended to pay little attention to findings from a formal research process from which they feel alienated.

\section{DISTORTION OF MEANING AND THE POLITICS OF DISCOURSE}

As scientists develop and refine systems of concepts and theories that address a chosen area of study, a discourse evolves - a network of linguistic terms and references which embodies the emerging understanding of what is important in terms of categories and distinctions, processes and causal relationships. The social and territorial dimensions of this process mean that a discourse reflects the values and prejudices of those who forge it. It emerges within a context of conflicts of interest between different role-players and inevitably reflects the outcome of power relations between opposing parties. In these conflicts, roleplayers strategically shift between a collaborative and an adversarial stance in order to promote their own positions. The appeal to "science" or "scientific principles" can therefore have different meanings, depending on which pole is being used as a reference. The adversarial pole is of particular value when seeking to dismiss the arguments or claims of opponents. There is thus a politics of discourse and a politics of evidence (Larner, 2004).

In the area of research methodology, there are multiple, competing discourses and an ongoing discourse politics. Sadly the development of multivariate group statistical methods and the growing technology that allowed huge number crunching analyses led to the emergence of a research climate in which there was an overestimation of what could be achieved by quantitative multivariate group analysis and a systematic marginalization of qualitative observations and the single case within the social sciences in general (Mitchell, 1983). In psychology in particular, over the last 80 years or so, a position that emphasized measurement, objectivity and the establishment of conclusive proof rapidly achieved dominance and its protagonists successfully exploited the adversarial pole to establish and maintain their position. Consequently, the rich contextualized knowledge that can be gained from case studies and case-based research came to be undervalued.

This historical process was supported by a discourse in which the meaning of words was systematically distorted. Politically loaded terms became so part of the everyday debate that they began to slip glibly off the tongues even of those who rejected this dominance. Once entrenched, the discourse itself served to communicate tacit assumptions about the value of different research methodologies, in a manner which perpetuated the marginalization of methodologies that were case-based, contextual and interpretative and the disempowerment of the practitioner and the practitioner's perspective. Some of these distortions will be examined in the following sections.

\section{The "Gold Standard" as an Absolute Value}

In the literature on clinical interventions, the metaphor of the "gold standard" is used in several different ways to point to the search for quality and excellence with which all scientific and professional activity should be concerned. However, the connotation of a fixed and 
Collaborative Versus Adversarial Stances in Scientific Discourse:

Implications for the Role of Systematic Case Studies

D.J.A. Edwards

Pragmatic Case Studies in Psychotherapy, http://pcsp.libraries.rutgers.edu

Volume 3, Module 1, Article 2, pp. 6-34, 03-01-07 [copyright by author]

absolute standard is problematic in contexts where absolute certainty is not available, and the term "gold standard" can easily be appropriated as a rhetorical device that implies exaggerated claims about absolute certainty. In research on the implementation and evaluation of clinical interventions, there are three uses of the term, one in the area of assessment and diagnosis, one with respect to interventions, and the third, which most concerns us here, in discussions of research methodology.

In the area of assessment and diagnosis, the term refers to an instrument which is currently regarded as the leader in the field in terms of validity. When Deacon and Abramowitz (2005) examined the psychometric properties of the Yale-Brown ObsessiveCompulsive scale (Y-BOCS), their factor analysis did not confirm the findings of previous studies. They concluded that although the scale is regarded as the "'gold standard' measure of OCD severity" (p. 574), there are problems with its structure which call for modifications to the scoring of the inventory for future practice. Utian et al (2005), who evaluated an assessment instrument for Female Sexual Dysfunction, observed that currently "[d]iagnosis made by [expert] clinicians using their own specific method is accepted as the gold standard" (p. 272). Their aim was to improve on this by validating a set of self-report questionnaires that could be administered by a larger number of trained interviewers. Similarly, in the domain of intervention, the term refers to whatever is regarded as current best. For example, in an article entitled "Is Lithium still the gold standard in the treatment of bipolar disorders?" Möller (2003) discusses the advantages and disadvantages of lithium and other newer drugs.

In practice, in both these cases, the metaphor of a "gold standard" is misleading since it clearly refers to "the best currently available" rather than to some absolute "best possible." However, the connotation of an absolute standard, carries the tacit implication that the diagnostic instrument or intervention in question has a high degree of authority and stability. In the examples given above, this implication is clearly unfounded since researchers cited pointed to significant limitations in the Y-BOCS or the way sexual dysfunction is assessed in women. In the case of lithium in the treatment of bipolar disorders, Möller (2003, p. 114) pointed out that there are contexts in which other agents may be appropriate, for example for "non-classical bipolar patients" or for situations in which there is concern about long term side effects.

In methodologies for the evaluation of clinical treatments, the term "gold standard" has been routinely used to refer to the randomized controlled trial (RCT) in which, at its best, there is strict randomization, double-blind administration of treatments and a placebo control group. Use of the term "gold standard" here has a number of implications. The first is that the RCT is the "best possible" methodology, standing at the top of a hierarchy of methodologies of varying quality with all other methods ranked well below it. The second is that only RCTs provide meaningful evidence for the value of an intervention, and that, by extension, research with other methodologies is of limited value. This position ignores several well known limitations of the RCT. For example, in practice, the criterion of double-blinding can seldom be met in research on psychotherapeutic interventions. It is virtually impossible for therapists to be blind to the nature of the intervention they are offering, and although clients may not understand the difference between "active" treatments such as cognitive behavior therapy (CBT) and "inactive" treatments that are offered as an equivalent of a pharmacological 
Collaborative Versus Adversarial Stances in Scientific Discourse:

Implications for the Role of Systematic Case Studies

D.J.A. Edwards

Pragmatic Case Studies in Psychotherapy, http://pcsp.libraries.rutgers.edu

Volume 3, Module 1, Article 2, pp. 6-34, 03-01-07 [copyright by author]

placebo, the latter are likely to have limited credibility and offering them can be ethically questionable (Rains and Penzien, 2005). Other limitations of RCTs are discussed in a later section.

Theorists who recruit the "gold standard" metaphor into their discourse typically ignore the ambiguity of the term hidden in the connotations of the economic context from which it is taken. The gold standard was abandoned as the basis for the world's economic system in the decade preceding World War II. It was simply not practical to organize the values of commodities and currencies around a fixed and absolute value for a single item, gold. Attempts to reinstate it after the war were unsuccessful and it was finally dropped in 1971. Gold is still very valuable and important, but currently its price has to take its place alongside other components of the economic process within a comprehensive multilayered system.

This is a good analogy for the RCT as a research method. It is a very important tool that provides certain kinds of evidence that can be found in no other way. However, like other research methods, it has its limitations with respect to the kind of questions it can answer, and it does not do justice to its strengths to expect it to do things that it cannot. Thus, Salkovskis (2002) expressed concern that clinical interventions were being evaluated solely on the basis of outcome data from RCTs followed by meta-analyses of multiple studies, warning that these were "inflexible and inappropriate ways of selecting and reducing data" (p. 4). He advocates a holistic perspective which allows for "a multi-dimensional approach to clinical science." This approach will be examined later in this article.

Several recent commentators have used the counter metaphor of "fools gold" to highlight concerns about the uncritical use of the "gold standard" metaphor and about the dangers inherent in a rigid epistemological system that sought to give an absolute place to a single strategy (Cohen, 2005; Hyde, 2004; Sternberg, 2006). "Fool's gold" is an iron ore containing pyrite (iron sulphide) that may be mistaken for gold-bearing rock by inexperienced prospectors. Prospectors who make this mistake are destined to be disappointed that the hoped for idealized solution to their life problems has eluded them.

\section{Distortion of the Term "Anecdotal"}

Another widely used term whose meaning is subject to systematic distortion is "anecdotal." Those pushing an ideological framework in which multivariate group quantitative research is the only valid and meaningful form of knowledge production routinely employ it to exclude case-based observations and even case studies from the domain of science. Sheldrake (2004, p. 5), a biologist, points out that "anecdote" comes from a Greek word meaning "not published." As such its original meaning is simply an unpublished observation. However it has other connotations in everyday language: The Merriam-Webster Online Dictionary (2006) defines it as "a usually short narrative of an interesting, amusing, or biographical incident." In ordinary conversation it is particularly "amusing" incidents that are referred to as anecdotes, with the implication that it is the incident's entertainment value rather than its truth value that is most important, and even an expectation that the facts might be stretched somewhat in order to capitalize on the former. When made by experienced practitioners familiar with scientific progress in a particular field, observations of single 
Collaborative Versus Adversarial Stances in Scientific Discourse:

Implications for the Role of Systematic Case Studies

D.J.A. Edwards

Pragmatic Case Studies in Psychotherapy, http://pcsp.libraries.rutgers.edu

Volume 3, Module 1, Article 2, pp. 6-34, 03-01-07 [copyright by author]

episodes within cases may provide evidence that is just as important as that gleaned from multivariate group comparison research. To call such evidence "anecdotal", with its connotation of amusing and perhaps far-fetched tales over dinner is not helpful to science. It is effectively a rhetorical device designed to exclude clinical experience or case-based evidence from scientific debate, under the guise of a scientific principle.

Sheldrake (2004, p. 5) observes that when anecdotes (in the neutral sense of unpublished observations) are published, "they are promoted to the rank of case histories ... [which] serve as the essential foundation of experience on which further research can be built." Unfortunately, while such published case observations have been central to the development of medicine and psychotherapy, they may still be dismissed as "anecdotal" by critics who have an ideological axe to grind and are ignorant of Greek. This is a distortion of the meaning of the word "science" itself. A moment's reflection will disclose that much of the technology of today's psychotherapy was discovered by clinicians observing one or a few single events in interaction with their clients. Many of them are so widespread and so obvious that they were probably discovered independently time and again by different practitioners and theorists from the time when psychotherapy emerged as a definable enterprise in the mid nineteenth century (Ellenberger, 1970). A client felt relief when the therapist helped him/her identify a previously unacknowledged feeling; a client felt more in control when a therapist helped him/her to see that his/her anxiety was based on exaggerated and unexamined appraisals; a client felt relieved of longstanding guilt when a therapist examined their contribution to the event in question using guided discovery and constructing a pie chart to quantify the different contributing factors. Without observations from cases it is impossible to develop a scientifically based clinical practice of psychotherapy. As Stiles (Lampropoulos et al., 2002) observes:

the theories that psychotherapy researchers investigate were developed by practitioners based on their clinical observation and experience with innovative interventions. Most approaches were practiced long before they were formally researched, and psychotherapy research is interesting because it studies approaches that are being practiced. (2002, p. 1253)

Observations from within cases do not, by themselves, create effective psychotherapies that can address the needs of all who seek help with psychological problems. However they provide the building blocks out of which effective therapies are built. Bromley (1986, p. ix) rightly calls systematic observations of cases "the bedrock of scientific investigation." Eells (2006, this module) provides valuable historical examples of their contribution to medical science, and, in Biology, Sheldrake (2004, p. 4) points out how Charles Darwin was fascinated by the observations of natural phenomena from everyday life made by "naturalists, explorers, colonial administrators, missionaries and others with whom he corresponded all over the world." Apparently Darwin "studied publications like Poultry Chronicle and The Gooseberry Grower's Register ... [and] grew 54 varieties of gooseberry himself."

A carefully documented observation from a single case can stand by itself as a coherent piece of data, even though at the time its full significance cannot be appreciated and its underlying causes explained. This can be illustrated by a historical example from a context much simpler than the typical scenario of a psychotherapy session, where a single observation 
Collaborative Versus Adversarial Stances in Scientific Discourse:

Implications for the Role of Systematic Case Studies

D.J.A. Edwards

Pragmatic Case Studies in Psychotherapy, http://pcsp.libraries.rutgers.edu

Volume 3, Module 1, Article 2, pp. 6-34, 03-01-07 [copyright by author]

provided a crucial test of a significant point of theory. Do heavy objects fall faster than light ones? The common sense of everyday experience suggests the answer "Yes," and this was what Aristotle thought. However, some 2000 years later with the development of a proper science of mechanics this was no longer obvious and Galileo argued that all objects fall with the same velocity and acceleration unless affected by other factors such as air pressure or resistance. With the invention of the air pump around 1650 it was possible to create a vacuum tube and perform the crucial experiment: a feather and a coin were both dropped in a vacuum and both fell at the same rate. For those of us used to large numbers of trials, the calculation of distributions and the complexities of statistical decision making it is sobering to consider that this experiment only had to be done once! Of course it can be done again and again and replicated at other times and places. However, as Eckstein (1975) observed in a discussion of case studies in political science, it was clear when it was done the first time that Galileo was right.

In mechanics, it is possible to set up situations in which all relevant variables can be stabilized or controlled, and it is easier than in the context of psychotherapy to set up experiments where a single observation may be enough. Because of the diversity and complexity of human behavior and experience, simple recipes in psychotherapy invariably fail to benefit everybody, but it is a mistake to extrapolate from that to the conclusion that single observations are of no value and can make no contribution to the development of scientific knowledge. Many events that take place within psychotherapy are comprehensible and coherent within an understanding of the process of the therapy as a whole and can often be reliably understood within their context.

Such contextualized knowledge is not easily obtained within RCTs. Although they have an important place in evaluating clinical interventions, they are an exceedingly blunt instrument when it comes to the management of individual cases. Miller and Miller (2005, p. 71) cite a study in which researchers calculated that, if RCTs were the only source of scientific evidence available to accurately guide clinical decisions about the different options available for treating Alzheimer's disease, "127 RCTs would have to be done on 63,500 patients over a 286 year period.” This emphasizes a point made by Edwards, Dattilio \& Bromley who observe:
A limitation of multivariate studies is that the statistical procedures they employ deduce the properties of a population from those of a sample; they cannot deduce from a sample the properties of individual cases ... Yet this is what practitioners need to know. The RCT that shows that a treatment helps 40 percent of clients does not tell me if the client who enters my office today is one of them. (2004, p. 595)

Goldberg (2006) makes the same point in discussing the guidelines for the treatment of depression from The National Institute for Clinical Excellence (NICE) in the UK. NICE conducts reviews to determine best practice in the treatment of a range of physical and psychological disorders. Appropriately determination of efficacy of treatments is based on a critical review of results of RCTs and meta-analyses. However, as Goldberg (2006) observes, this is not enough to determine treatment of an individual case: 
Collaborative Versus Adversarial Stances in Scientific Discourse:

Implications for the Role of Systematic Case Studies

D.J.A. Edwards

Pragmatic Case Studies in Psychotherapy, http://pcsp.libraries.rutgers.edu

Volume 3, Module 1, Article 2, pp. 6-34, 03-01-07 [copyright by author]

Patients do not go to doctors for evidence-based medicine (EBM), they go for patientbased evidence. Rather than be told what the best treatment is for the average member of the population (EBM), they want to know what is the best treatment for them, with their particular problems and idiosyncracies. (2006, p. 13)

While some patient-based evidence can be derived from RCTs, much of it will be better obtained from other kinds of study, especially case studies.

\section{Distortion of the Meaning of "Empirical"}

Another word whose meaning is regularly used in a distorted way is "empirical" often twisted to mean something demonstrated in a study with a multivariate research design (Edwards et al. 2004). For example, Jeffrey Young, commenting on the theory and principles set out in Cognitive Therapy for Personality Disorders: A Schema-Focused Approach, first published in 1990 and in its third edition in 1999, remarked apologetically:

The constructs proposed here have not yet been tested empirically, and so must be viewed as speculative. $(1999$, p. 7$)$

The fact is that Young's theory building and clinical methods are based on extensive and systematic study of a large body of clinical case material and the constructs of his theory are extremely well grounded in behavioral and phenomenological data. In a 1989 paper, I argued that the development of schema-focused cognitive therapy offered a fine role model for rigorous clinical theory development (Edwards, 1989). However I also pointed out that the data on which the theory had been built had largely not been published: the large numbers of cases, carefully formulated, reflected on, and examined in peer discussions, over many years that had served to ground the development and refinement of the approach.

Even now, with the publication of a major exposition of the theory and practice (Young, Klosko, and Weishaar, 2003), information about these is confined to case vignettes and a few more extended case presentations (McGinn, Young, \& Sanderson, 1995; McGinn \& Young, 1996; Young \& Flanagan, 1998; Young \& Gluhoski, 1996; Young \& Lindemann, 1992). What is available for inspection by the scientific community is merely the tip of the iceberg. This is not because Young and his colleagues were negligent or chose to suppress information. It has been part of the normative practice in psychotherapy research that case studies are considered unimportant, of little evidential value, and not worthy of publication. Nevertheless, Young's disclaimer about the empirical grounding of his theory is misleading. It is true that, when the book was published, the efficacy of the interventions had not yet been tested in randomized controlled trials, and this may be what Young actually meant. But, as should become clear from the arguments of this paper, that is quite different from saying that the constructs had not been empirically tested.

A further example of the distortion of the term "empirical" is a distinction drawn by Goldfried at a panel at the 2000 conference of the Society for Psychotherapy Research (SPR) between "clinical observation and empirical research" (Lampropoulos et al, 2002, p. 1245). He suggests that it is important to let "our research grow out of clinical observations." What is 
Collaborative Versus Adversarial Stances in Scientific Discourse:

Implications for the Role of Systematic Case Studies

D.J.A. Edwards

Pragmatic Case Studies in Psychotherapy, http://pcsp.libraries.rutgers.edu

Volume 3, Module 1, Article 2, pp. 6-34, 03-01-07 [copyright by author]

remarkable is not that Goldfried makes this excellent suggestion but the implication that this is not the normative approach to psychotherapy research. At the 2006 SPR conference, in an open discussion on insight in psychotherapy, Adele Hayes introduced her contribution by saying, "This was supposed to be an empirical talk so I bought lots of statistics and graphs." This spontaneous expression of the distortion of the meaning of "empirical" shows how deeply embedded it has become in the tacit ideology underlying psychotherapy discourse in which multivariate research is regarded as superior to case-based or qualitative approaches. During another open discussion on case study methodology, Louis Castonguay sought to challenge this with the creative phrase "empirical imperialism," drawing on a previous conference presentation in which he and a colleague criticized the overemphasis on multivariate group research (Castonguay and Borkovec, 2005). While this phrase succinctly captures the essence of the problem, it also buys into the distortion of the term empirical, since it implies that only multivariate research qualifies to be considered as empirical.

In part these distortions are based on uninformed generalizations from technical terms such as "empirically validated treatment" (EVT) and "empirically supported treatment" (EST) which have been used to flag interventions for whose value there is exceptionally strong evidence. In their very balanced discussion of ESTs, Chambless and Hollon (1998) chose to move away from the former (EVT) because of its connotation of absolute certainty. An EST is defined as one for which there is clear evidence for efficacy for a specific target population, that is to say the treatment has been shown to work better than no treatment at a clinically significant level for patients presenting with a particular clinical problem such as panic disorder, depression, or marital discord. Efficacy needs to be established by RCTs and replicated at more than one site. There should also be evidence for effectiveness (transportability to routine clinical settings) and of cost-effectiveness. These criteria for evaluation of treatments are valuable in determining policy about mental health provision and making decisions about training, but there is nothing in this definition of EST to imply that other kinds of research are not valuable or that they are not "empirical". Chambless and Hollon specifically note that they are not denying

the importance of other factors such as the therapeutic alliance, as well as client and patient variables that effect the process and outcome of psychological therapies (p. 7)

and specifically acknowledge the role of "[n]aturalistic studies of actual clinical practice" (p. 15) within the wider research process.

In his President's Column in The Clinical Psychologist, Gerald Davison (2006), draws attention to the slippery and misleading use of the term "empirical" and points out the need to correct it. He reminds readers that it means "based on experience" and that includes the experience of practitioners in the field. It also includes experience based on systematic observation of individual cases. Edwards et al. (2004) pointed out that case studies

usually preserve the complexity of the real-life situation far better than multivariate studies in which the context and details of everyday clinical phenomena are easily obscured or lost altogether. When properly applied, they confront empirical facts in a way that is often more direct than in applications of quantitative multivariate methods where 
Collaborative Versus Adversarial Stances in Scientific Discourse:

Implications for the Role of Systematic Case Studies

D.J.A. Edwards

Pragmatic Case Studies in Psychotherapy, http://pcsp.libraries.rutgers.edu

Volume 3, Module 1, Article 2, pp. 6-34, 03-01-07 [copyright by author]

individual experience is simplified and filtered through scales and operational definitions or distorted by experimental manipulation. (2004, p. 590).

In much of the research methodology literature there is a focus on the weaknesses of case study methodology and its strengths typically downplayed, while there is less emphasis on the limitations involved in the quantification of variables and the interpretation of multivariate studies. The dangers involved in drawing conclusions from quantification and statistical analysis are alluded to in the famous warning contained in the phrase "lies, damned lies and statistics" made famous by Mark Twain in the late nineteenth century. Twain believed that the phrase had originated with Benjamin Disraeli, although it was first used in print by a statistician in the 1890 's, and is often used by statisticians themselves to point to the limitations of statistical inference. It is a serious mistake to equate empiricism with quantification and statistical analysis. As Sheldrake (2004) comments,

To brush aside what people have actually experienced is not to be scientific, but unscientific. Science is founded on the empirical method, that is to say on experience and observation. (2004, p. 5)

In practice, good clinical work proceeds in the same way as good scientific work. Twentyfive years ago, in a special issue of the Journal of Consulting and Clinical Psychology, Kiesler (1981) pointed out that the observation and conceptualization that occur in clinical assessment are typical of a scientific exploration of a new phenomenon, and Hayes (1981) that clinical decisions are made by applying or extending existing knowledge in the same way that is done in any area of formal research.

\section{"Clues", "Evidence" and "Proof"}

Discussions about how scientific theories are developed and tested are often marked by confusion with respect to the concepts of "evidence" and "proof". Science, as Miller and Miller (2005, p. 70) observe, seeks for "objective certainty" or "proof" of propositions on the basis of "irrefutable evidence." "For a hypothesis to be proved," they continue, "or a theory to become a theorem, the evidence supporting it must be irrefutable." In practice, however, irrefutable evidence is the exception rather than the rule, and when it is obtained it is usually the result of a long process of investigation with many converging steps contribute to the final conclusion.

Detectives seeking to solve a crime looks for "clues," observations that suggest hypotheses about how the crime was committed and who the criminal is. The word comes from an older word "clew" which means a ball of thread and is derived from the legend of Theseus who found and killed the Minotaur at the heart of the Cretan Labyrinth and found his way back by following a thread he had unrolled as he went deeper and deeper into it. In fact and in fiction the good detective is the one who can see that apparently trivial information may be a clue, something that leads from darkness and confusion to the open light of day. In the same way astute clinicians can see the implications of apparently trivial or meaningless aspects of a client's verbal or non-verbal behavior and use these as clues to find their way through the 
Collaborative Versus Adversarial Stances in Scientific Discourse:

Implications for the Role of Systematic Case Studies

D.J.A. Edwards

Pragmatic Case Studies in Psychotherapy, http://pcsp.libraries.rutgers.edu

Volume 3, Module 1, Article 2, pp. 6-34, 03-01-07 [copyright by author]

maze of fragmented information that confronts them when they assess and formulate a complex case.

For detectives and clinicians, various pieces of evidence must be evaluated and their meaning integrated into an overall picture. For the psychotherapist this is the basis for the case formulation in which working hypotheses are identified and tested and refined by the psychotherapy process (Eells, 2006, this module; Persons and Tompkins, 1997). In the legal context, an advocate develops an organized structure of evidence and arguments into a "factual matrix" (Miller and Miller, 2005, p. 73). The detective, the therapist and the advocate all have to "make their case" and submit it to the scrutiny of others who will critically examine the quality of the evidence they present and the degree to which it can support the conclusion offered. This is as much a reality in science as in these applied settings.

A clear distinction between evidence and proof is essential for an applied clinical science where theory does not take the form of theorems in the shape of mathematical formulas that define relationships between variables. Clinical practice is based on a body of knowledge built on vast numbers of observations and systematized into an organized body of concepts, distinctions, propositions and hypotheses (Edwards et al., 2004; Eells, 2006, this module; Hilliard, 1993). Bromley (1986) likens this to case law as developed in jurisprudence; it is the basis of the "grounded theory" approach widely used in psychology and sociology (Strauss and Corbin, 1994) and Fishman's (2005) "pragmatic psychology." This knowledge is refined on an ongoing basis through multiple forms of dialogue between theory and practice and draws on a range of different kinds of evidence.

In practical contexts, decisions have to be made in the absence of irrefutable proof. In the court room, judges and juries must weigh evidence, informed by consensually agreed principles. This is particularly true in the area of public health where intervention cannot wait for absolute proof of efficacy. "Best practice" implies that clinicians are responsible for taking decisions about intervention on the basis of the best available evidence. Similarly, the "precautionary principle" (Miller and Miller, 2005, p. 70) recognizes that it is not appropriate to wait for absolute proof that an intervention is harmful before withdrawing it from the public domain. Responsible decision making between courses of action always involves a calculation about the probabilities of harm or benefit likely to follow each course of action, based on weight and quality of evidence. At the pole of practical knowledge, the search is not for irrefutable proof of propositions, but for the steady building of the quantity and quality of evidence in support of theoretical principles that guide effective practice. While an adversarial stance reminds us to continually question, to avoid complacency, and to be aware that current best practice can be improved, the all-or-none thinking that often accompanies it can contribute to an inflexible and simplistic approach which fails to acknowledge the complexity of the process. Paradoxically, statistical analysis has been misused in the service of claims for absolute certainty - despite the fact that the main aim of statistical decision theory is to provide an analysis of how to make decisions rationally in the absence of such certainty. 


\section{EVIDENCE-BASED PRACTICE AND COMPLEMENTARITY OF RESEARCH METHODS}

In the evaluation of psychological interventions, the framework of evidence based practice (EBP) provides a more balanced perspective. While the framework used to define ESTs focuses on research designed to establish the efficacy of clinical treatments, EBP is practitioner-oriented and addresses the problems of everyday clinical decision making. There is a recognition that clinical decisions are best made on the basis of a careful evaluation of available evidence taken from a variety of relevant sources. EBP in medicine was defined in the British Medical Journal by Sackett, Rosenberg, Gray, Haynes and Richardson (1996) as:
... the conscientious, explicit and judicious use of current best evidence in making decisions about the care of individual patients [which] means integrating individual clinical expertise with the best available external clinical evidence from systematic research. (1996, p. 71)

Although Davison (2006) warns that this kind of definition is "as full of promise and ingenuity as it is fraught with problems" since it does not tell us how we get that evidence from research and how we evaluate it, substantial guidelines have already been offered in the literature.

For example, Salkovskis (2002) set out a framework for research that can provide the basis for the development of "empirically grounded clinical interventions" (p. 4). Clinicians working in practice build theory on the basis of clinical experience in order to understand cases and plan interventions. This process can be extended by conducting formal case studies, and aspects of the emerging theory can be formally tested in experimental studies. As treatments are formalized their efficacy can be evaluated in RCTs. Thus, several complementary processes work together and it is a mistake to privilege one aspect over others. Salkovskis pointed out that this is not a new approach. It has been the methodological basis of the development of interventions in cognitive behavior therapy for several decades.

This kind of multidimensional approach is the basis for the report of the American Psychological Association's (2005) Presidential task force on Evidence-based practice in psychology (EBPP). EBPP was defined as "the integration of the best available research with clinical expertise in the context of patient characteristics, culture and preferences" (p. 5). In a methodological commentary on a case published in an earlier module of Pragmatic Case Studies in Psychotherapy (PCSP), a member of that task force, Carol Goodheart (2005), summarized some of the implications of this report for clinical case studies. She observed,

... multiple types of research evidence ... contribute to effective psychological practice. Among the sources of research evidence are systematic individual case studies involving both quantitative and qualitative process and outcome data, such as those associated with PCSP. (2005, p. 2)

One of the central aims of PCSP is to bring into focus important questions about how to conduct and interpret case studies so that they can assume their place as a central piece of the evidence-base. 
Implications for the Role of Systematic Case Studies

D.J.A. Edwards

Pragmatic Case Studies in Psychotherapy, http://pcsp.libraries.rutgers.edu

Volume 3, Module 1, Article 2, pp. 6-34, 03-01-07 [copyright by author]

\section{Figure 1: Interrelationships Among Different Kinds of Research Activity}

Following Salkovskis (2002), Edwards et al. (2004) identified three broad categories of research method: Case-based studies, Experimental studies and RCTs. We expanded a figure from Salkovskis' paper, reproduced below in Figure 1, to illustrate their relationship with each other and with other aspects of the scientific process and their complementary roles within the process of clinical knowledge building. These included major contextual institutions that contribute to the development of clinical theory: Clinical Practice (A) and Science (H), including Non-Clinical Scientific Theory (G). Clinical Practice (A) is, on the one hand, informed by the scientific method $(\mathrm{H})$, for example in respect of concerns about evidence and evaluating alternative explanations; while, on the other hand, clinical practice serves as the basis for Applied Clinical Theory (E). This, in turn serves as the basis for Clinical Treatment Models (D), which may range from broad principles and approaches to detailed treatment manuals and which are put to the test informally within Clinical Practice (A).

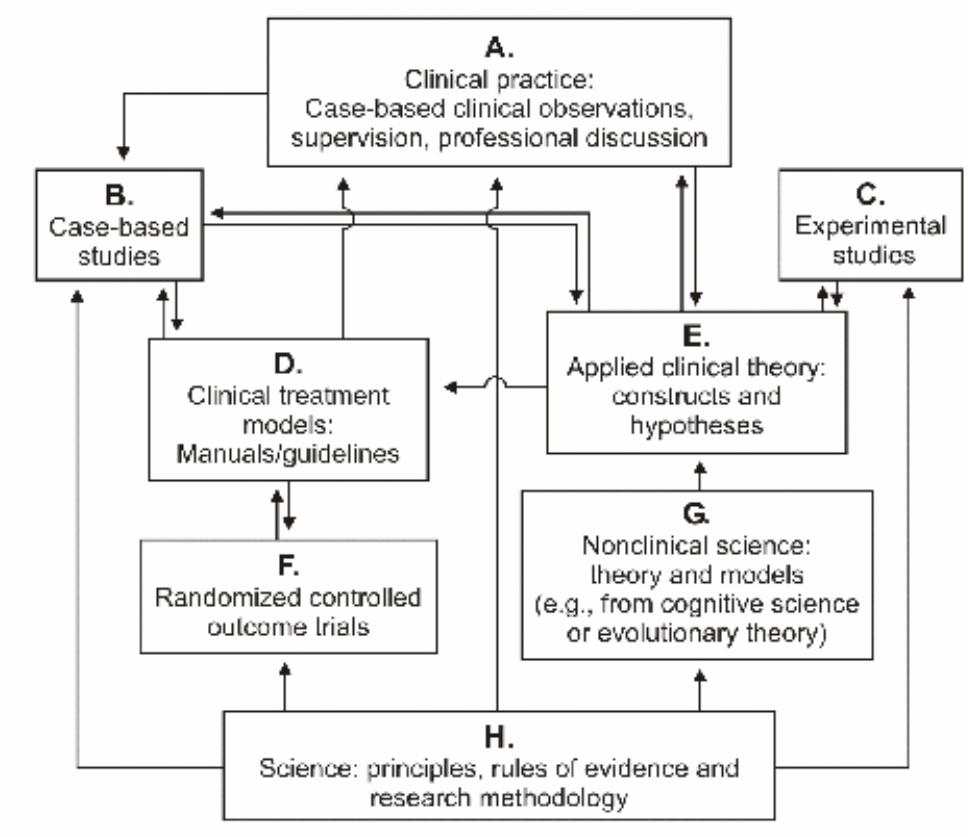

Figure 1. Research activity and the systematic development of clinical practice.

From "Devcloping evidence-based practice: The role of case-based research" by D.J.A. Edwards. F.M. Dattilio, \& D.B. Bromley, 2004. Professional Psychology: Rescarch and Practice, 35, page 591.

Copyright 2004 by the American Psychological Association. Reprinted with permission.

In addition, Clinical Theory (E) and Clinical Treatment Models (D) that serve as the basis for Clinical Practice (A) can be elaborated, refined and tested by means of a range of research models based on the principles of Science $(\mathrm{H})$. Case-based studies $(\mathrm{B})$, 
Implications for the Role of Systematic Case Studies

D.J.A. Edwards

Pragmatic Case Studies in Psychotherapy, http://pcsp.libraries.rutgers.edu

Volume 3, Module 1, Article 2, pp. 6-34, 03-01-07 [copyright by author]

Experimental studies $(\mathrm{C})$ and $R C T s(\mathrm{~F})$ have complementary and different roles to play in the overall process.

Table 1: Expanding the Logical Links Between Research Method and Research Goals

In Table 1 below, the framework in Figure 1 is expanded into seven categories of research method which contribute in different and complementary ways to the development, refinement and evaluation of clinical interventions. The table summarizes the extent to which the research method draws on everyday clinical practice, and the kinds of questions it is most likely to be helpful in answering. Each of these categories will be examined below and illustrated by examples, several from recent research on the development of focused cognitive therapies for posttraumatic stress disorder (PTSD), and, in particular, the work of Ehlers and Clark (2000; Clark and Ehlers, 2005).

Table 1. Types of Research Activity that Contribute to the Development, Refinement and Evaluation of Clinical Treatment Models

\begin{tabular}{|l|l|l||l|l|l|l|}
\cline { 2 - 7 } \multicolumn{1}{c|}{ Type of research } & $\begin{array}{l}\text { Normal } \\
\text { clinical } \\
\text { practice }\end{array}$ & $\begin{array}{l}\text { Formal } \\
\text { research } \\
\text { activity }\end{array}$ & $\begin{array}{l}\text { Builds } \\
\text { and } \\
\text { refines } \\
\text { clinical } \\
\text { theory }\end{array}$ & $\begin{array}{l}\text { Develops } \\
\text { and refines } \\
\text { models for } \\
\text { clinical } \\
\text { practice }\end{array}$ & $\begin{array}{l}\text { Evidence } \\
\text { for } \\
\text { effective- } \\
\text { ness }\end{array}$ & $\begin{array}{l}\text { Evidence } \\
\text { for } \\
\text { efficacy }\end{array}$ \\
\hline 1. Brief case observations & $\sqrt{ }$ and/or $\sqrt{ }$ & $\sqrt{ }$ & $\sqrt{ }$ & \\
\hline 2. Systematic case studies & $\sqrt{ }$ and/or $\sqrt{ }$ & $\sqrt{ }$ & $\sqrt{ }$ & $\sqrt{ }$ & $\sqrt{ }$ \\
\hline $\begin{array}{l}\text { 3. Case-based qualitative } \\
\text { analysis }\end{array}$ & & $\sqrt{ }$ & $\sqrt{ }$ & $\sqrt{ }$ & $\sqrt{ }$ & \\
\hline $\begin{array}{l}\text { 4. Multivariate studies of } \\
\text { clinically relevant variables }\end{array}$ & & $\sqrt{ }$ & $\sqrt{ }$ & $\sqrt{ }$ & \\
\hline 5. Analogue experiments & & $\sqrt{ }$ & & & $\sqrt{ }$ & \\
\hline 6. RCTs & & $\sqrt{ }$ & & & & \\
\hline $\begin{array}{l}\text { 7. Practice-based-evidence } \\
\text { research }\end{array}$ & & $\sqrt{ }$ & & & & \\
\hline
\end{tabular}

\section{Brief Case Observations or Vignettes}

Brief case observations or case vignettes provide examples of specific kinds of phenomena significant for a psychological understanding of particular clinical problems. These serve as the basis for the classification of different kinds of experience which is fundamental to theory development (Mahrer, 1988). Ehlers, Hackmann and Michael (2002) give two striking vignettes of survivors of motor vehicle accidents which show how sensory cues may trigger flashbacks to a trauma memory which may be experienced as coming "out of the blue." The one: 
Collaborative Versus Adversarial Stances in Scientific Discourse:

Implications for the Role of Systematic Case Studies

D.J.A. Edwards

Pragmatic Case Studies in Psychotherapy, http://pcsp.libraries.rutgers.edu

Volume 3, Module 1, Article 2, pp. 6-34, 03-01-07 [copyright by author]

was relaxing in his garden when he suddenly became very anxious and had intrusions of headlights coming towards him. Only later he realized that these were triggered by a bright patch of sunlight on his lawn. (2002, p. 407)

The other was a woman who, while washing dishes, turned to the left to take a tea towel and was filled with fear. This was accompanied by images of blue and yellow. On investigation, this turned out to be a flashback. Her car had been hit from behind by a blue and yellow bus which she had seen on turning her body to the left. When she experimented with turning to the right in the same way the flashback was not triggered. Such observations initially serve as a basis for theory building. Later, similar phenomena seen in other cases confirm the theory's more general applicability.

More extensive case vignettes are offered by Grey, Young and Holmes (2002) in an exposition of clinical methods used in the guided reliving intervention. These not only document the kinds of interventions used and the responses of clients to them, but also provide examples of the kinds of clinical observations (mostly unpublished) which have formed the basis of the intervention and contributed to the development of the underlying theory. Systematic examination of selected case observations across a large number of cases is the basis of other qualitative research methods discussed in section 3 below.

\section{Systematic Case Studies}

Systematic case studies can be used to test or refine Clinical Treatment Models (see item D in Figure 1). These studies are an extension of clinical practice into which mechanisms are built for improving quality control and enhancing the evidential power of the data. The intensive study of a single case enables the client's response to the various components of an intervention to be examined closely. This allows for the study of individual differences in response, and the generalizability of the intervention to cases with a range of different characteristics. This is valuable in effectiveness research which examines the performance of treatment models in routine clinical settings (discussed further under 7 below). This research process also allows for the progressive refinement and elaboration of treatment models so that they can cater for a wider range of clients. Difficulties that arise with some clients in the implementation of a treatment can be identified, and strategies developed for identifying and addressing them in the future.

Systematic case studies can provide evidence for efficacy too, although they do not invariably do so. For example, there would be evidence for efficacy if an intervention was brief (to reduce the probability of alternative explanations of outcome) and was followed by clinically meaningful improvement in a case which met the following conditions: (a) there was a trustworthy baseline showing no improvement over weeks or months, (b) the individual had been the target of previous interventions that had been ineffective, (c) no other external lifeevent could account for the change, and (d) there was qualitative data from the process of the therapy to link the change to the processes set in motion by the intervention. Strategies such as a multiple baseline design where symptoms are targeted in a specific order can also yield evidence for efficacy (Kratochwill, Mott and Dodson, 1984). However many clinical problems do not lend themselves to such designs. 
Collaborative Versus Adversarial Stances in Scientific Discourse:

Implications for the Role of Systematic Case Studies

D.J.A. Edwards

Pragmatic Case Studies in Psychotherapy, http://pcsp.libraries.rutgers.edu

Volume 3, Module 1, Article 2, pp. 6-34, 03-01-07 [copyright by author]

It is useful to distinguish between the clinical methodology and the research methodology employed in case-based studies. The former is usually in the form of a set of procedures for assessment, treatment planning and ongoing decision making in the implementation of an intervention. In the case of cognitive therapy for PTSD as developed by Ehlers and Clark and their group, no formal manual is yet available, but detailed guidelines for assessment, formulation and treatment have been published (Clark and Ehlers, 2005; Ehlers and Clark, 2000; Ehlers, Clark, Hackmann, McManus and Fennell, 2005; Ehlers et al 2002; Grey et al, 2002; Mueller, Hackmann, and Croft, 2004). Their clinical methodology is flexible and driven by the case formulation. Although there are clear principles and procedures, treatment is individualized on the basis of the idiosyncratic presentation of each client. The ongoing process of assessment and intervention is monitored at regular supervision team meetings. This accords with the model for case-formulation driven cognitive therapy as described by Persons, Roberts, Zalecki, and Brechwald (2006) for depression.

The research methodology brings scientific principles to bear on the processes of data collection, data reduction and data interpretation. Ehlers and Clark's cases are all videotaped and several measures of PTSD and depressive symptoms are measured repeatedly from the first assessment through to follow-up. Many of the publications draw on material from individual cases to show how their theoretical understanding of the factors that maintain PTSD as well as their model for assessment and treatment were tested, evaluated and refined. There is thus a close and reciprocal interaction between clinical work and research activity.

Around 75 of such systematic cases form the basis of clinical trials published by Ehlers and Clark so far (Ehlers et al, 2003; Ehlers et al, 2005), and others are currently being conducted. The majority of their cases have been part of RCTs. Others formed a consecutive series of 19 cases reported by Ehlers et al (2005), but only limited information about individual cases is provided. Quantitative analyses of the data served as the basis of several conclusions: (1) there was evidence that the treatment was more effective than previous treatments because the effect size for the combined sample was 2.8 , twice that found in evaluation of previous treatments; (2) there was evidence that treatment gains were well-maintained over the following six months; and (3) there was evidence that the intervention model was very acceptable, since they had far fewer dropouts than reported in most previous studies of PTSD treatment (only one, who withdrew for reasons not related to the treatment).

Although this case series played an important role in the development of their treatment model, the detailed case material has not been prioritized for publication as case studies. Although there are several case studies of treatment of PTSD from other researchers (Batten \& Hayes, 2005; Cigrang, Peterson, \& Schobitz, 2005; Davis, De Arellano, Falsetti, \& Resnick, 2003; Paunovic, 2002; Pole \& Bloomberg-Fretter, 2006; Schulz, Marovic-Johnson, \& Huber, 2006; Trzepacz \& Luiselli, 2004), no full case studies have been published by Ehlers and Clark's group. As observed above, this has been the standard way of reporting the development of most forms of structured psychological treatment, and leaves an unfortunate lacuna in the literature. 
Collaborative Versus Adversarial Stances in Scientific Discourse:

Implications for the Role of Systematic Case Studies

D.J.A. Edwards

Pragmatic Case Studies in Psychotherapy, http://pcsp.libraries.rutgers.edu

Volume 3, Module 1, Article 2, pp. 6-34, 03-01-07 [copyright by author]

\section{Case-Based Qualitative Research}

Case-based qualitative research strategies differ from systematic case studies in that they draw on a set of cases for which focused qualitative data is available relevant to a particular theme or research question. They do not draw on the whole history of each case. Such studies enable researchers to focus on and conceptualize specific aspects of the therapy process. In this kind of research information from all cases is included in the analysis and theoretical interpretation. This contrasts with studies in which means of groups form the basis of analysis and where the significance of the idiosyncratic experience of an individual may easily be lost. For example, Hackmann, Ehlers, Speckens and Clark (2004) and Holmes, Grey and Young (2005) used cases from the Ehlers and Clark database of PTSD cases to study the content of intrusive imagery. Hackmann et al classified the content of intrusive imagery as reported by 22 patients, using a system based on the theory of the kinds of memory that give rise to intrusions. These included: two kinds of "warning signal" (stimuli present shortly before the traumatic event and stimuli that were associated with a moment when there was a marked shift for the worse in the meaning of what was happening); two kinds of positive experience (images of all being well before the trauma occurred and of moments when the meaning became better, e. g. on realizing they or another person were not severely hurt); moments when patients wished they had acted differently; elements from previous traumatic events; dissociative experiences such as seeing oneself outside one's body. They hypothesized that what these have in common is that they are the kinds of moment which patients have difficulty connecting "with new information that is important for their meaning" (p. 237), which is why they are likely to be experienced as intrusions.

Holmes at al (2005) related intrusive imagery in 32 patients to the content of "hotspots," moments of most intense emotional distress, identified during reliving therapy sessions. Although fear and dissociation (numbing, feeling unreal) were the most common emotional responses, sadness, anger, helplessness, shame, guilt and disgust were also regularly reported. The meaning of hotspots was coded into 21 distinct categories which were in turn organized into a smaller number of overall themes, such as: (a) uncertain threat (unease, confusion, and on-going threat), (b) threat of death or injury to self or other, (c) control and reasoning (which included problem-oriented coping as well as thoughts about injustice and revenge), (d) abandonment, (e) self-blame/criticism, and (f) and cognitive avoidance (disbelief, dissociation ). All specific emotions or themes were associated with intrusions in some cases, and were non-intruding in others. The authors hypothesized that hotspots were associated with moments of "peak distress" and high arousal, "causing the most disruption to emotional processing" (p. 14). These findings supported the hypothesis already advanced (e. g. by Grey at al, 2002) that anxiety and fear are not the only emotions that call for therapeutic attention. They showed that there is a diverse range of factors that may need to be addressed in a therapy, and this supports the argument that it is important to formulate the particular, idiosyncratic features of each case.

A study of patients with high levels of hopelessness at assessment by McMillan, Barkham and Hardy (2006) illustrates the kind of research question which could well be addressed by such case-based qualitative research. They found that rapid reduction in hopelessness in the first few sessions predicted good treatment outcome, but a measure of 
extremism in belief endorsement which was intended to tap rigid, dichotomous thinking failed to predict outcome. They suggested that the study be repeated using other measures of possible correlates of non-responsive hopelessness. While this strategy might be of value, an in-depth qualitative examination of a series of cases would likely be productive for examining hypotheses about the kinds of processes that underlie non-responsive hopelessness and the kinds of interventions likely to resolve it. Likely candidates for non-responsive hopelessness that emerged from the clinical experience of participants in a discussion that followed this paper included: (1) general demoralization compounded by the avoidance and anhedonia that characterises depression, (2) investment in self-protective coping strategies that lead to emotional numbing and a sense of meaninglessness, and (3) the presence of powerful internalized critical voices that neutralize any attempt at self-enhancement. Each process found to contribute to underlying non-responsive hopelessness would probably call for a different strategic intervention and such interventions could also be profitably examined on a case by case basis.

\section{Multivariate Group Studies of Clinically Relevant Variables}

Multivariate group studies offer another route to evaluating and testing clinical theory. Measurements are taken of several variables which have been identified as likely to be relevant to psychological processes that maintain a disorder and relationships among them are examined. These can include self-report scales, cognitive tests and physiological measures. The data are analyzed by subdividing the sample into groups and comparing means or using correlation coefficients and/or factor analysis. For example, measures of PTSD symptoms and several cognitive variables believed to be relevant to the maintenance of PTSD were given by Dunmore, Clark and Ehlers (2001) to 57 victims of physical or sexual assault within four months of the assault and 6 and 9 months later. In line with the findings of previous research, variables that predicted symptom severity at follow-up included mental defeat, mental confusion and detachment at the time of the trauma, negative appraisal of trauma sequelae and maladaptive control strategies involving avoidance and safety-seeking.

Halligan, Michael, Clark and Ehlers (2003) reported a cross-sectional study in which they interviewed assault survivors 3 months or more after the event and classified them into three groups, those who never developed PTSD, those who had PTSD one month post assault but who had recovered by the time of the interview, and those who still had PTSD. Group comparisons and correlational analyses were performed on the data. They also reported a longitudinal study which used a correlational analysis: assault survivors were assessed within 3 months of the trauma and again 3, 6, and 9 months later. Both studies provided evidence that the more cognitive processing during the trauma is characterized by dissociation, data-driven processing and lack of self-referent processing, the greater is the disorganization of the trauma narrative. Factor analysis suggested that the concept of dissociation is too broad and may better "be recast in terms of experimental psychology research" (p. 429). Findings in both these studies are relevant to the testing and refinement of Ehlers and Clark's clinical theory and treatment model. 
Collaborative Versus Adversarial Stances in Scientific Discourse:

Implications for the Role of Systematic Case Studies

D.J.A. Edwards

Pragmatic Case Studies in Psychotherapy, http://pcsp.libraries.rutgers.edu

Volume 3, Module 1, Article 2, pp. 6-34, 03-01-07 [copyright by author]

\section{$\underline{\text { 5. Analogue Experiments }}$}

In analogue experiments, researchers examine responses to a situation which has some similarities to real life situations of interest. Nixon and Bryant (2006) showed that trauma survivors with Acute Stress Disorder (ASD) demonstrated more panic, dissociation and maladaptive interpretations of the arousal produced by a hyperventilation provocation test than trauma survivors without ASD or controls. This is in line with the hypothesis that fearful misinterpretations of stress symptoms contribute to the development and maintenance of ASD. Halligan, Clark and Ehlers (2002) showed research participants a film of the gruesome aftermath of a motor vehicle accident. Individuals more prone to data-driven processing experienced more disturbing intrusions during the following week and found them more distressing. They also reported more traffic-related fears, more avoidance and more arousal symptoms. This provided evidence for the role of data-driven processing in predisposing individuals to PTSD.

Davies and Clark (1998b) used a film about a traumatic fire. A higher level of intrusions over the following week was associated with negative mood (depression, anger, anxiety) during the film, tendency to suppress negative thoughts and beliefs about vulnerability to fire. The experiment provides evidence for a number of hypotheses already present in existing theories relevant to PTSD: first, that negative intrusive imagery is a normal response to traumatic events, second, that negative emotion at the time of a trauma renders individuals vulnerable to later intrusions, and therefore to developing PTSD, and third that suppression of thoughts and images increases rather than decreases the presence of intrusions. Participants in a second study (Davies and Clark, 1998a) either watched the film of the traumatic fire or a film about polar bears. Intrusions were monitored for two periods after the film. In the first, some participants were asked to suppress intrusive thoughts about fire or polar bars, while others were not. In the second they were all asked merely to monitor their thoughts. In the first period the suppression group experienced fewer thoughts of fire of polar bears than the controls. They had successfully suppressed the naturally occurring images. However, in the second period, for the traumatic film, the suppression group showed a "rebound" effect and reported more intrusions than the control group, while there was no difference between suppression group and controls who had watched the polar bear film. The findings support the hypothesis that thought suppression of trauma-related thoughts results in an intensification of these thoughts, a mechanism believed to contribute to the maintenance of PTSD.

\section{$\underline{\text { 6. Randomized Controlled Trials }}$}

$R C T s$ are designed as a rigorous means of testing the efficacy of clinical treatment models or manuals. They answer the question of whether an intervention is efficacious, that is to say is it responsible for actively bringing about change. The design enables alternative explanations of positive effects of treatment to be ruled out. Randomization to different treatment or control conditions rules out explanations in terms of selection bias. An explanation in terms of spontaneous recovery can be ruled out by comparing an active treatment with a waiting list control condition (Ehlers et al, 2005). An explanation in terms of non-specific therapy factors can be ruled out by comparison with a non-specific intervention. For example, Bryant, Harvey, Dang, Sackville and Basten (1998) and Bryant, Sackville, Dang, 
Collaborative Versus Adversarial Stances in Scientific Discourse:

Implications for the Role of Systematic Case Studies

D.J.A. Edwards

Pragmatic Case Studies in Psychotherapy, http://pcsp.libraries.rutgers.edu

Volume 3, Module 1, Article 2, pp. 6-34, 03-01-07 [copyright by author]

Moulds and Guthrie (1999) showed that a structured cognitive-behavioral intervention was more effective than supportive counseling in treating Acute Stress Disorder. Ehlers et al (2003) compared their active treatment for PTSD with repeated assessments. Efficacy can be compared across studies using the statistic Cohen's $d$ which measures effect-size. Thus, Ehlers and her group reported effect-sizes for their treatment for PTSD which were considerably higher than those obtained in studies of other forms of treatment in two RCTs and their case series (Ehlers et al, 2003; Ehlers et al, 2005).

As Table 1 shows, RCTs have an irreplaceable role in establishing the efficacy of a treatment. However, they also have limitations. They provide very limited information relevant to the mechanism of change or the refinement of the details of an intervention. In addition, RCTs are seldom conducted with samples which are representative of caseloads in routine practice settings (Lueger, 2002; Shapiro and Paley, 2006). Furthermore, because RCTs are expensive to set up, the current evidence from RCTs is unbalanced in that there is far more information on efficacy for medications than for psychotherapies, and within psychotherapy far more evidence on CBT interventions than for other modalities such as psychodynamic and systemic therapies (Larner, 2004; Shapiro and Paley, 2006).

\section{Practice-Based-Evidence Research}

Research on practice-based evidence (Barkham et al, 2006; Stiles, Barkham, Twigg, Mullin, Mellor-Clark and Cooper, 2006 ) addresses whether a treatment works in everyday clinical settings, that is the treatment's effectiveness or transportability (Lueger, 2002). Treatments shown to be efficacious in RCTs may not be equally effective in practice because of limitations on therapist training, limitations on resources, or because clients present obstacles to treatment not encountered in the research sample (Schoenwald and Hoagwood, 2001). In one kind of effectiveness study, mean scores and effect-sizes from a sample treated in a routine clinic can be compared with those obtained in the RCTs. For example, Gillespie, Duffy, Hackmann, and Clark (2002) evaluated Ehlers and Clark's cognitive therapy for PTSD in a clinical service in Omagh, Northern Ireland in the aftermath of the 1998 terrorist bomb which killed 29 people and injured 370. In a series of 91 patients they obtained an effect size of 2.47, comparable to that obtained in the RCTs (Ehlers et al, 2003; Ehlers et al, 2005). This kind of result is not typical however. Results from routine practice often fall short of those obtained in research trials (Doubleday and Hey, 2004). Thus Shapiro and Paley (2006) studied the effectiveness of interpersonal psychodynamic therapy in routine practice and found that their results fell short of those obtained in a research trial but that they were equivalent for those reported for CBT in practice settings.

Another strategy is to use group comparison designs to compare the gains made by samples of patients treated with different kinds of therapy. Stiles, et al (2006) found that despite the evidence for the efficacy of CBT in RCTs, it performed no better than personcenterd therapy or psychodynamic therapy in routine practice across over 50 sites in the UK National Health Service. This kind of research shows the limitations of basing decisions about provision of treatment on data from RCTs. However, it offers no information about effectiveness for specific clinical presenting problems or of specific treatment approaches 
within the broad approaches and there is no information about the extent to which treatments accorded with current accepted standards within the different modalities.

\section{Summary}

In sum, the different research methods summarized in Table 1 can each play a substantive and complementary role in developing and evaluating clinical theories, clinical models of practice, and clinical outcomes. In the examples provided, it was seen that all the seven kinds of data have contributed to the development, refinement and scientific testing of the theoretical framework of Ehlers and Clark's cognitive model of PTSD and of the cognitive therapy treatment manual that is derived from it. For example,

*** brief case observations (1) have shown the specificity of sensory cues in triggering flashbacks;

*** systematic case studies (2) have been helpful in illustrating how a case formulation process with PTSD individuals can take into account the idiosyncratic nature of the mechanisms and contexts behind their PTSD reactions;

*** case-based qualitative analysis (3) has helped to pinpoint the range of idiosyncratic content of intrusive imagery that PTSD clients experience in "reliving" sessions.

*** multivariate studies of clinically relevant variables (4) have shown that in contrast to idiosyncratic processes, there are some overarching mechanisms across PTSD clients, e.g., the more the cognitive processing during a trauma is characterized by dissociation, data-driven processing, and lack of self-referent processing, the greater is the disorganization of the trauma narrative.

*** analogue experiments (5) have supported the hypothesis of a general tendency across individuals for thought suppression of trauma-related thoughts to result in an intensification of these thoughts, a mechanism believed to contribute to the maintenance of PTSD.

*** RCTs (6) by Ehlers and Clark's group have provided promising evidence of its efficacy, since they obtained effect-sizes that were considerably higher than those obtained in studies of other forms of treatment with this population.

*** practice-based-evidence research (7) from the study in Omagh, Northern Ireland of treatment within a clinical service in the aftermath of a devastating, terrorist bomb in 1998 has yielded promising evidence for the effectiveness of Ehlers and Clark's model for assessment and treatment of PTSD cases, since they obtained an effect size comparable to that obtained in their RCTs. 


\section{GUIDELINES FOR CONDUCTING SCIENTIFIC CASE STUDIES}

This survey of methodologies has drawn out the complementary roles of different research strategies in developing valid clinical knowledge and the significance of systematic case studies as one of these strategies. The strength of the Evidence-Based Practice in Psychology (EBPP; APA, 2006) framework is that, in acknowledging this, it provides an opportunity to bridge the longstanding gulf between practitioners and researchers. A greater emphasis on conducting case studies will contribute to this because it enhances the perceived credibility of clinical theory and its relation to practice.

Several developments are necessary to ensure that case-based observations take their place as a significant factor in the process of knowledge development, as outlined in the EBPP framework. First, there is a need to remove prejudice and bias from the discourses used to discuss research methodology by correcting the kinds of distortions discussed above, for example with respect to the use of words like "empirical" and "anecdotal" and to clarify the role of "evidence" in the process of knowledge building and to be cautious about idealized notions of "proof".

Second, there should be more training in applying case-based methodology and in writing case narratives. Students and practitioners frequently express considerable interest in case studies because of their perceived clinical relevance and the insight they give into psychological processes as they unfold across time and would often see conducting a case study as more in accord with their long term goals than conducting multivariate group research. However, at one open discussion session during the 2006 conference of the Society for Psychotherapy Research, a participant expressed concern that writing case studies was "too difficult." In part this reflects the limited training typically given in this kind of research, and in part the fact that the construction of a case narrative and the logic of drawing conclusions from it often calls for a different type of complexity than involved in drawing conclusions from more familiar, group comparison designs.

Third, there is an urgent need to establish consensus about the general principles of case-based research. It is important to recognize that case study research is not a method with fixed strategies or a set of determined procedures. It is rather a set of principles for generating information from cases that will be of evidential value in addressing specific research questions relevant to clinical practice. The literature on clinical case studies as well as that on qualitative research includes a range of well tested practical steps that can form the basis of good quality case studies and there is already a considerable convergence of ideas on the following (Edwards et al, 2004; Fishman, 2005; Lampropoulos et al, 2002; Mahrer, 1998):

(i) It is important to conduct a comprehensive assessment and to use it as a basis for a careful case formulation upon which the planning of interventions is based (Fishman, 2005; Eells, 2006, this module).

(ii) Data need to be collected carefully and systematically. Voice or even video recordings provide a data source that can be returned to again and again to test out the accuracy of 
Collaborative Versus Adversarial Stances in Scientific Discourse:

Implications for the Role of Systematic Case Studies

D.J.A. Edwards

Pragmatic Case Studies in Psychotherapy, http://pcsp.libraries.rutgers.edu

Volume 3, Module 1, Article 2, pp. 6-34, 03-01-07 [copyright by author]

case narratives or interpretations about psychological processes. Repeated applications of quantitative measures provide a check on subjective impressions about whether progress is being made. Self-report questions are usually employed for this. Bilsbury and Richman (2002) argue that it is more important that self-report scales accurately tap the psychological processes relevant to change than that they be standardized on large samples. Scales standardized on large samples have the advantage that they allow statistical benchmarking and cross-case comparisons. However, they may measure such broad factors that they have limited use clinically. Bilsbury and Richman (2002) show how to design scales that explicitly address the idiosyncratic features of an individual case (for a brief summary of their procedure, with an example, see Edwards, 2006, in this Journal). As understanding of particular clinical problems deepens, so researchers are able to develop customized self-report instruments that are sensitive to more specific targets for change, behaviorally, cognitively and emotionally. Although it is often more complex to arrange, physiological data can also sometimes be collected on an ongoing basis.

(iii) Quality control procedures can be built in to protect against the common (and often valid) criticisms of case studies, especially where clinician and researcher are the same. For example, narratives may be flawed by the researcher's biases (even unwittingly), episodes inconsistent with the researcher's theoretical position may be omitted, or claims about an unfolding psychological process may go beyond the evidence of the data. These problems can be addressed by having independent checking of steps by a third party and by having research outcome interviews conducted by an independent interviewer during and post treatment.

(iv) Data analysis should be used to investigate a variety of issues, such as: (a) the claims of existing theory, and (b) obstacles to treatment or processes that call for extension of what is presented in research treatment manuals. Studies of treatment failures are of particular value in this regard. Case studies can also be used to investigate the extent to which a research-based treatment is transportable to real world settings where resources are limited, practitioners have less than ideal levels of training and the client population is more diverse than in the research studies.

Finally, there is a need for more case studies incorporating a good standard of quality control to be written and published. As observed above, valuable case data that is used in research trials to develop and evaluate interventions is currently not routinely made available to the wider community of researchers and practitioners. Case study researchers could consider collaborating with research groups to write up selected cases (Fishman, 2005). Even in psychotherapy process research, reports often provide extensive case examples, but there are few systematic case studies. For example, Safran and Muran's (2000; Safran, Muran, Samstag and Stevens, 2001) research on alliance ruptures is based on a systematic case-based methodology and has succeeded in describing a range of different types of rupture that can occur and in testing out and refining strategies appropriate to different kinds of rupture. Safran, Muran, Samstag and Winston (2005) provide two extended case vignettes, but some fuller systematic case studies would provide the research community with the opportunity to evaluate the application of the approach within the context of the complexity of the relationship between individual client and individual therapist. 
More case studies from routine clinical practice settings could also be written if researchers worked with practitioners to ensure the implementation of appropriate quality controls, and undertook the tasks of writing out a full case narrative, graphing scores on repeated measures and engaging fully with the literature (Edwards et al, 2004).

\section{REFERENCES}

Merriam-Webster Online Dictionary (2006). Anecdote. Available: http://www.mw.com/dictionary/anecdote [On-line].

American Psychological Association (2005). Report of the 2005 Presidential Task Force on Evidence Based Practice. Available at http://www.apa.org/practice/ebpreport.pdf [Online].

Barkham, M., Twigg, E., Leach, C., Mullin, T., Mellor-Clark, J., Bower, P. et al. (2006). Building an interface with practice-based evidence by rewiring efficacy trials: More from the dodo bird? Paper presented at the 37th Annual Conference of the Society for Psychotherapy Research, University of Edinburgh, June.

Batten, S. V. \& Hayes, S. C. (2005). Acceptance and Commitment Therapy in the Treatment of Comorbid Substance Abuse and Post-Traumatics Stress Disorder. Clinical Case Studies, 4, 246-262.

Bilsbury, C. D. \& Richman, A. (2002). A staging approach to measuring patient-centerd subjective outcomes. Acta Psychiatrica Scandinavica, 196 (Suppl. 414), 5-40.

Bromley, D. B. (1986). The case study method in psychology and related disciplines. Chichester: John Wiley.

Bryant, R. A., Harvey, A. G., Dang, S. T., Sackville, T., \& Basten, C. (1998). Treatment of acute stress disorder: A comparison of cognitive behavioral therapy and supportive counseling. Journal of Consulting and Clinical Psychology, 66, 862-866.

Bryant, R. A., Sackville, T., Dang, S. T., Moulds, M., \& Guthrie, R. (1999). Treating acute stress disorder: An evaluation of cognitive behavior therapy and supportive counseling techniques. American Journal of Psychiatry, 156, 1780-1786.

Castonguay, L. G. \& Borkovec, T. (2005). Practice Research Networks: An antidote for empirical imperialism. Paper presented at the Annual Meeting of the American Psychological Association.Washington, D.C.(August).

Chambless, D. \& Hollon, S. D. (1998). Defining empirically supported therapies. Journal of Consulting and Clinical Psychology, 66, 7-18.

Cigrang, J. A., Peterson, A. L., \& Schobitz, R. P. (2005). Three American troops in Iraq: Evaluation of a brief exposure therapy treatment for the secondary prevention of combat-related PTSD. Pragmatic Case Studies in Psychotherapy, 1, Module 2, Article 1, 1-25. Available: http://pcsp.libraries.rutgers.edu

Clark, D. M. \& Ehlers, A. (2005). Posttraumatic stress disorder: From cognitive theory to therapy. In R.L.Leahy (Ed.), Contemporary cognitive therapy (pp. 141-160). New York: Guilford.

Cohen, D. (2005). Clinical psychopharmacology trials: 'Gold standard' or fool's gold. In S.A.Kirk (Ed.), Mental disorders in the social environment: Critical perspectives (pp. 347-367). New York, NY: Columbia University Press. 
Collaborative Versus Adversarial Stances in Scientific Discourse:

Implications for the Role of Systematic Case Studies

D.J.A. Edwards

Pragmatic Case Studies in Psychotherapy, http://pcsp.libraries.rutgers.edu

Volume 3, Module 1, Article 2, pp. 6-34, 03-01-07 [copyright by author]

Dattilio, F. M. \& Norcross, J. C. (2006). Psychotherapy integration and the emergence of instinctual territoriality. Archives of Psychiatry and Psychotherapy, 8, 5-16.

Davis, J. L., De Arellano, M., Falsetti, S. A., \& Resnick, H. S. (2003). Treatment of Nightmares Related to Post-Traumatic Stress Disorder in an Adolescent Rape Victim. Clinical Case Studies, 2, 283-294.

Davies, M. I. \& Clark, D. M. (1998a). Predictors of analogue post-traumatic intrusive cognitions. Behavioural and Cognitive Psychotherapy, 26, 303-314.

Davies, M. I. \& Clark, D. M. (1998b). Thought suppression produces a rebound effect with analogue post-traumatic intrusions. Behaviour Research and Therapy, 36, 571-582.

Davison, G. C. (2006). President's column: An invitation to ausdeinandersetzen about the evidence-based practices in psychology task force report. The Clinical Psychologist, $59,1-4$.

Deacon, B. J. \& Abramowitz, J. S. (2005). The Yale-Brown Obsessive Compulsive Scale: Factor analysis, construct validity, and suggestions for refinement. Anxiety Disorders, 19, 573-585.

Doubleday, E. \& Hey, C. (2004). Is statistical significance enough? Behavioural parent training programmes in real life. Clinical Psychology, 37, 5-9.

Dunmore, E., Clark, D. M., \& Ehlers, A. (2001). A prospective investigation of the role of cognitive factors in persistent Posttraumatic Stress Disorder (PTSD) after physical or sexual assault. Behaviour Research and Therapy, 39, 1063-1084.

Eckstein, H. (1975). Case study and theory in political science. In F. I. Greenstein \& W. Polsby (Eds.), Handbookof political science - Volume 7: strategies of enquiry (pp. 79137). Reading, Mass.: Addison-Wesley.

Edwards, D. J. A. (1989). Case study research method: The hidden cornerstone of theory and practice in cognitive therapy. Poster presentation at the World Congress of Cognitive Therapy, Oxford, UK.

Edwards, D. J. A. (2006). How the case of Vumile contributes to the evidence base for cognitive therapy with social phobia as an empirically grounded clinical intervention. Pragmatic Case Studies in Psychotherapy, 2, module: 1, Article 6, pp.1-17.

Edwards, D. J. A., Dattilio, F., \& Bromley, D. B. (2004). Developing evidence-based practice: The role of case-based research. Professional Psychology: Research and Practice, 35, 589-597.

Eells, T. (2006). Case formulation and pragmatic case studies. Pragmatic Case Studies in Psychotherapy [Online], Vol. 3(1), Article 3. Available: http://hdl.rutgers.edu/1782.1/pcsp_journal.

Ehlers, A. \& Clark, D. M. (2000). A cognitive model of posttraumatic stress disorder. Behaviour Research and Therapy, 38, 319-345.

Ehlers, A., Clark, D. M., Hackmann, A., McManus, F., \& Fennell, M. (2005). Cognitive therapy for post-traumatic stress disorder: development and evaluation. Behaviour Research and Therapy, 43, 413-431.

Ehlers, A., Clark, D. M., Hackmann, A., McManus, F., Fennell, M., Herbert, C. et al. (2003). A randomized controlled trial of cognitive therapy, a self-help booklet, and repeated assessments as early interventions for posttraumatic stress disorder. Archives of General Psychiatry, 60, 1024-1032.

Ehlers, A., Hackmann, A., \& Michael, T. (2004). Intrusive re-experiencing in posttraumatic stress disorder: Phenomenology, theory and therapy. Memory, 12, 403-415. 
Ehlers, A., Hackmann, A., Steil, R., Clohessy, S., Wenninger, K., \& Winter, H. (2002). The nature of intrusive memories after trauma: The warning signal hypothesis. Behavior research and therapy, 40, 995-1002.

Ellenberger, H. F. (1970). The discovery of the unconscious: The history and evolution of dynamic psychiatry. New York: Basic Books.

Fishman, D. B. (2005). Editor's Introduction to PCSP - From Single case to database: A new method for enhancing psychotherapy practice. Pragmatic Case Studies in Psychotherapy [Online], 1, Module 1, Article 2. Available: http://pcsp.libraries.rutgers.edu

Gillespie, K., Duffy, M., Hackmann, A., \& Clark, D. M. (2002). Community based cognitive therapy in the treatment of post-traumatic stress disorder following the Omagh bomb. Behaviour Research and Therapy, 40, 345-357.

Giorgi, A. (1986). The "Context of discovery/context of verification" distinction and descriptive human science. Journal of Phenomenological Psychology, 17, 151-166.

Goldberg, D. (2006). The "NICE" Guideline on the treatment of depression. Epidemiologia e Psichiatria Sociale, 15, 11-15.

Goodheart, C. D. (2005). Placing psychotherapy case studies within the framework of the APA evidence-based practice in psychology (EBPP) model. Pragmatic Case Studies In Psychotherapy [on line], 1, Module 3, Article 2. Available: http://pcsp.libraries.rutgers.edu.

Grey, N., Young, K., \& Holmes, E. (2002). Cognitive restructuring within reliving a treatment for peritraumatic emotional "hotspots" in posttraumatic stress disorder. Behavioural and Cognitive Psychotherapy, 30, 37-56.

Hackmann, A., Ehlers, A., Speckens, A., \& Clark, D. M. (2004). Characteristics and content of intrusive memories in PTSD and their changes with treatment. Journal of Traumatic Stress, 17, 231-240.

Halligan, S. L., Clark, D. M., \& Ehlers, A. (2002). Cognitive processing, memory, and the development of PTSD symptoms: Two experimental analogue studies. Journal of Behavior Therapy and Experimental Psychiatry, 33, 73-89.

Halligan, S. L., Michael, T., Clark, D. M., \& Ehlers, A. (2003). Postraumatic stress disorder following assault: The role of cognitive processing, trauma memory, and appraisals. Journal of Consulting and Clinical Psychology, 71, 419-431.

Hayes. S. C. (1981). Single case experimental design and empirical clinical practice. Journal of Consulting and Clinical Psychology, 49, 193-211.

Hilliard, R. B. (1993). Single case methodology in psychotherapy process and outcome research. Journal of Consulting and Clinical Psychology, 61, 373-380.

Holmes, E. A., Grey, N., \& Young, K. A. D. (2005). Intrusive images and "hotspots" of trauma memories in Posttraumatic Stress Disorder: an exploratory investigation of emotions and themes. Journal of Behavior Therapy and Experimental Psychiatry, 36, 3-17.

Hyde, P. (2004). Fools gold: Examing the use of gold standards in the production of research evidence. British Journal of Occupational Therapy, 67, 89-94.

Kuhn, T.S. (1962). The structure of scientific revolutions. Chicago: University of Chicago Press.

Kiesler, D. J. (1981). Empirical clinical psychology: Myth or reality? Journal of Consulting and Clinical Psychology, 49, 212-215. 
Collaborative Versus Adversarial Stances in Scientific Discourse:

Implications for the Role of Systematic Case Studies

D.J.A. Edwards

Pragmatic Case Studies in Psychotherapy, http://pcsp.libraries.rutgers.edu

Volume 3, Module 1, Article 2, pp. 6-34, 03-01-07 [copyright by author]

Kratochwill, T. R., Mott, S. E., \& Dodson, C. L. (1984). Case study and single case research in clinical and applied psychology. In A. S. Bellack \& M. Hersen (Eds.), Research methods in clinical psychology (pp. 55-99). New York: Pergamon.

Lampropoulos, G., Goldfried, M. R., Castonguay, L. G., Lambert, M. J., Stiles, W. B., \& Nestoros, J. N. (2002). What kind of research can we realistically expect from the practitioner? Journal of Clinical Psychology, 58, 1241-1264.

Larner, G. (2004). Family therapy and the politics of evidence. Journal of Family Therapy, $26,17-39$.

Lueger, R. J. (2002). Practice-informed research and research-informed psychotherapy. Journal of Clinical Psychology, 58, 1265-1276.

Mahrer, A. R. (1988). Discovery orientated psychotherapy research: Rationale and aims. American Psychologist, 43, 694-702.

McGinn, L. K., Young, J. E., \& Sanderson, W. C. (1995). When and how to do longer term therapy .... without feeling guilty. Cognitive and Behavioral Practice, 2, 187-212.

McGinn, L. K. \& Young, J. E. (1996). Schema-focused therapy. In P.Salkovskis (Ed.), Frontiers of cognitive therapy (pp. 182-207). New York: Guilford.

McMillan, D., Barkham, M., \& Hardy, G. (2006). Responsive hopelessness, extremism in belief endorsement and outcome in cognitive therapy for depression. Paper presented at the 37th Annual Conference of the Society for Psychotherapy Research, University of Edinburgh, June.

Miller, D. W. \& Miller, C. G. (2005). On evidence, medical and legal. Journal of American Physicians and Surgeons, 10, 70-75.

Mitchell, J. C. (1983). Case and situation analysis. Sociological Review, 31, 187-211.

Mitroff, I. I. (1974). The subjective side of science: A philosophical enquiry into the psychology of the Apollo moon scientists. New York: American Elsevier Publishing Co.

Möller, H-J. (2003). Is lithium still the gold standard in the treatment of bipolar disorders? European Archives of Psychiatry and Clinical Neuroscience, 253, 113-114.

Mueller, M., Hackmann, A., \& Croft, A. (2004). Post-traumatic stress disorder. In J. BennettLevy, G. Butler, M. Fennell, A. Hackmann, M. Mueller, \& D. Westbrook (Eds.), Oxford guide to behavioural experiments in cognitive therapy (pp. 183-201). Oxford: Oxford University Press.

Nixon, R. D. V. \& Bryant, R. A. (2006). Dissociation in acute stress disorder after a hyperventilation provocation test. Behavioural and Cognitive Psychotherapy, 34, 343349.

Paunovic, N. (2002). Prolonged exposure counterconditioning (PEC) as a treatment for chronic post-traumatic stress disorder and major depression in an adult survivor of repeated child sexual and physical abuse. Clinical Case Studies, 1, 148-169.

Persons, J. B., Roberts, N. A., Zalecki, C. A., \& Brechwald, W. A. G. (2006). Naturalistic outcome of case formulation-driven cognitive-behavior therapy for anxious depressed outpatients. Behaviour Research and Therapy, 44, 1041-1051.

Persons, J. B. \& Tompkins, M. A. (1997). Cognitive-behavioural case formulation. In T. D. Eells (Ed.), Handbook of Psychotherapy Case Formulation (first ed., pp. 314-339). London: Guilford.

Pole, N. \& Bloomberg-Fretter, P. (2006). Using control mastery therapy to treat major depression and posttraumatic stress disorder. Clinical Case Studies, 5, 53-70. 
Collaborative Versus Adversarial Stances in Scientific Discourse:

Implications for the Role of Systematic Case Studies

D.J.A. Edwards

Pragmatic Case Studies in Psychotherapy, http://pcsp.libraries.rutgers.edu

Volume 3, Module 1, Article 2, pp. 6-34, 03-01-07 [copyright by author]

Polkinghorne, D. E. (1986). Conceptual validity in a non-theoretical human science. Journal of Phenomenological Psychology, 17, 129-150.

Rains, J. C. \& Penzien, D. B. (2005). Behavioral research and the double-blind placebocontrolled methodology: Challenges in applying the biomedical standard to behavioral headache research. Headache, 45, 479-486.

Sackett, D., Rosenburg, W., Gray, J., Haynes, R., \& Richardson, W. (1996). Evidence-based medicine: What it is and what it isn't. British Medical Journal, 312, 71-72.

Safran, J., Greenberg, L. S., \& Rice, L. (1988). Integrative psychotherapy research and practice: Modeling the change process. Psychotherapy, 25, 1-17.

Safran, J. D. \& Muran, J. C. (2000). Resolving therapeutic alliance ruptures: diversity and integration. Journal of Clinical Psychology, 56, 233-243.

Safran, J. D., Muran, J. C., Samstag, L. W., \& Stevens, C. (2001). Repairing alliance ruptures. Psychotherapy, 38, 406-412.

Safran, J. D., Muran, J. C., Samstag, L. W., \& Winston.A. (2005). Evaluating alliance-focused intervention for potential treatment failures: A feasibility study and descriptive analysis. Psychotherapy: Theory, Research, Practice, Training, 42, 512-531.

Salkovskis, P. M. (2002). Empirically grounded clinical interventions: Cognitive-behavioral therapy progresses through a multi-dimensional approach to clinical science. Behavioural and Cognitive Psychotherapy, 30, 1-10.

Schoenwald, S. K. \& Hoagwood, K. (2001). Effectiveness, transportability, and dissemination of interventions: What matters when? Psychiatric Services, 52, 1190-1197.

Schulz, P. M., Marovic-Johnson, D., \& Huber, L. C. (2006). Cognitive-behavioural treatment of rape-and war-related posttraumatic stress disorder with a female, Bosnian refugee. Clinical Case Studies, 5, 191-208.

Shapiro, D. \& Paley, G. (2006). Evaluating psychodynamic interpersonal therapy in routine clinical practice. Paper presented at the 37th Annual Conference of the Society for Psychotherapy Research, University of Edinburgh, June.

Sheldrake, R. (2004). The sense of being stared at: and other aspects of the extended mind. London: Arrow Books.

Sternberg, R. J. (2006). Evidence-based practice: Gold standard, gold plated or fool's gold? In C. D. Goodheart, A. E. Kazdin, \& R. J. Sternberg (Eds.), Evidence-based psychotherapy: Where practice and research meet (pp. 261-271). Washington, DC: American Psychological Association.

Stiles, W. B., Barkham, M., Twigg, E., Mullin, T., Mellor-Clark, J., \& Cooper, M. (2006). Effectiveness of cognitive-behavioural, person-centred and psychodynamic therapies as practiced in United Kingdom mental health settings. Paper presented at the 37th Annual Conference of the Society for Psychotherapy Research, University of Edinburgh, June.

Strauss, A. \& Corbin, J. (1994). Grounded theory methodology: An overview. In N. K. Denzin \& Y. S. Lincoln (Eds.), Handbook of qualitative research (pp. 273-285). Thousand Oaks CA: Sage.

Strupp, H. H. (1981). Clinical research, practice, and the crisis of confidence. Journal of Consulting and Clinical Psychology, 49, 216-219.

Trzepacz, A. M. \& Luiselli, J. K. (2004). Efficacy of stress inoculation training in a case of posttraumatic stress disorder (PTSD) secondary to emergency gynecological surgery. Clinical Case Studies, 3, 83-92. 
Utian, W. H., Maclean, D. B., Symonds, T., Symons, J., Somayaji, V., \& Sisson, M. (2005). A methodology study to validate a structured diagnostic method used to diagnose female sexual dysfunction and its subtypes in postmenopausal women. Journal of Sex and Marital Therapy, 31, 271-283.

Young, J. E. (1999). Cognitive therapy for personality disorders: A schema-focused approach. (3rd ed.) Sarasota FL: Professional Resource Press.

Young, J. E. \& Flanagan, C. (1998). Schema-focused therapy for narcissistic patients. In E. F. Ronningstam (Ed.), Disorders of narcissism: Diagnostic, clinical, and empirical implications (pp. 239-268). Washington, DC: American Psychiatric Press.

Young, J. E. \& Gluhoski, V. (1996). Schema-focused diagnosis for personality disorders. In F. W. Kaslow (Ed.), Handbook of relational diagnosis and dysfunctional family patterns (pp. 300-321). New York: John Wiley.

Young, J. E., Klosko, J., \& Weishaar, M. E. (2003). Schema therapy: A practitioner's guide. New York: Guilford.

Young, J. E. \& Lindemann, M. D. (1992). An integrative schema-focused model for personality disorders. Journal of Cognitive Psychotherapy, 6, 11-23. 